Boise State University

ScholarWorks

9-1-2017

\title{
Albertsons Library Data Management Strategic Agenda Summer 2017 - Spring 2019
}

Amber Sherman

Boise State University

Heather Grevatt

Boise State University

Megan Davis

Boise State University

Michelle Armstrong

Boise State University

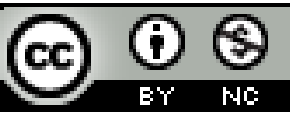

This work is licensed under a Creative Commons Attribution-Noncommercial 4.0 License 


\section{Albertsons Library Data Management Strategic Agenda Summer 2017 - Spring 2019}

Boise State University identifies research and creative activity as a Core Theme of its institutional mission. This concept is clarified through several objectives which outline the importance of transferring knowledge for "societal, economic, and cultural benefits". The university expects to produce work that has "substantial disciplinary impact and contributes to the overall reputation of the university," so that, "community members can connect with and benefit from our researchers, artists, and students." This core theme of scholarly contribution is further confirmed in the university's Goals and Strategies which detail specific activities Boise State will undertake. For example in goals 3 and 5, Boise State establishes its commitment to effective research and creative efforts by developing key competencies, building necessary infrastructures, and encouraging external funding and philanthropic support.

In consideration of these university goals, Albertsons Library is actively advocating for Boise State's research and creative activities through its own Strategic Plan. In Library Strategic Objective 4, Albertsons Library has committed to identifying "critical areas of needed Research Support then build expertise, capacity and services to meet these needs." Over the past several years, the library has pursued this goal through the development of research data management services detailed in the 2015-2016 Data Management Strategic Agenda - Final Report. These services have been built upon four principles:

- Research data is an asset

- Data management is an ongoing activity that happens throughout the life of the research project

- Researchers need "Point-of-Need" services

- The library strives to serve the whole university

The following Data Management Strategic Agenda continues this work by outlining activities Albertsons Library's Research Data Management Group will engage in over the next two years.

1. Continue to increase library capacity to deliver data management services.

- Activity 1.1: Assist library liaisons in building discipline-focused data management skills.

Description: The 2015-2016 Data Management Strategic Agenda Activity 1.4 provided training opportunities for all library staff across a broad spectrum of data management topics. Focusing these efforts to library liaisons and within specific disciplines will allow the library's Research Data Management Group to have a stronger return on instructional investment with measurable outcomes, such as liaison referrals for research data management support. The Research Data Management Group will investigate the best format for disciplinary support materials, develop appropriate support materials including a means of tracking use, and provide liaisons with 
sufficient knowledge of research data lifecycle resources to facilitate departmental referrals to the group.

Lead: Albertsons Library Research Data Management Group

Timeline: Summer 2017 - Summer 2018

- Activity 1.2: Work with university administrators and departmental partners to identify financial resources required to hire a metadata librarian.

Description: Metadata is an essential component of managing and making accessible research data. To help researchers establish systems for creating high quality, standards based metadata, librarians need in depth discipline specific knowledge of various metadata schema. Hiring a metadata librarian with the appropriate level of technical expertise would allow the library to provide these core data management services. To facilitate this activity, the Research Data Management Group will continue to advocate for the required financial resources, and provide use case information, service usage data, and other details about the impact and benefits of these services.

Lead: Michelle Armstrong

Timeline: Summer 2017 - Spring 2019

- Activity 1.3: With a focus on managing complex data issues and facilitating access to research software and technology, continue to develop the library's Research Data Management Group's skills and competencies.

Description: The Research Data Management Group continues to maintain a successful record of self-development. These efforts have helped establish research data management initiatives requiring progressively more sophisticated knowledge and skills including software, legal code, intellectual property, and contract issues. The Research Data Management Group will actively pursue formal learning opportunities and self-education activities with a focus on current skill gaps.

Lead: Albertsons Library Research Data Management Group Timeline: Summer 2017 - Spring 2019

- Activity 1.4: Ensure adequate and ongoing coverage for established research data management services by expanding and assigning specific responsibilities to the library's Research Data Management Group members.

Description: Boise State researchers have begun seeking assistance for data management services such as creating data management plans for grants and publicly sharing data sets as a part of journal article publishing activities. Often, these requests are time sensitive, requiring responses within one or two days time. To ensure that all library data management services are available 
when needed, the Research Data Management Group will cross-train on specific activities, identify individuals responsible for providing back-up services, and develop a process for notifying each other when additional coverage is needed.

Lead: Albertsons Library Research Data Management Group and Jean Barney Timeline: Summer 2017 - Fall 2017

- Activity 1.5: Create a cost estimate process to identify expenses associated with managing, preserving, and publishing research data.

Description: Effective costing allows researchers to more easily incorporate financial requests for data management services into their grant submissions. It also helps demonstrate measurable, value-added services performed by the Research Data Management Group. The Research Data Management Group will investigate and develop methods to estimate material and personnel costs associated with the research data lifecycle. They will also explore ways to make researchers aware of these costs and facilitate inclusion of research data management costs in grant submissions.

Lead: Heather Grevatt

Timeline: Summer 2017 - Spring 2018

\section{Utilizing strategic relationship building, help establish the necessary university infrastructure to support the creation, use, and dissemination of research data.}

- Activity 2.1: Facilitate the identification of core processes, policies, services, and resources related to research data.

Description: As awareness and use of research data management services has increased across campus, there has been a growing need to provide a comprehensive overview of the various activities, policies, and staff working in this area. In collaboration with campus partners, the library's Research Data Management Group will help create a model of the currently available data management resources. This model will help identify how the different campus units fit into the bigger research data picture and highlight where supports are lacking. It is also expected that once completed, the model will assist staff to provide more efficient responses and when appropriate, referrals to other campus groups.

Lead: Albertsons Library Research Data Management Group

Timeline: Summer 2017 - Spring 2018

- Activity 2.2: Working with campus partners, identify and receive needed approval for data related policies.

Description: Unifying university-level policies are necessary to transition from ad hoc adoption of best practices to consistent standards for research data acquisition, use, custody, maintenance, retention, access, and transfer at Boise State University. The library's Research Data Management 
Group will investigate current policy gaps, develop language for proposed policies, and work with campus partners to introduce data management policies through appropriate channels. Lead: Michelle Armstrong and Megan Davis

Timeline: Summer 2017 - Spring 2019

- Activity 2.3: Establish formal agreements with key university stakeholders to facilitate the effective management of Boise State's research data.

Description: Multiple stakeholders within the university bear the responsibility for research data management throughout the research lifecycle. Strategically positioning the library's data services with these stakeholders, including the Office of Sponsored Programs, will facilitate the effective management of the University's research output. To ensure these strategic collaborations are stable as staff change over time, the library's Research Data Management Group will, as needed, establish Memorandums of Understandings with campus stakeholders.

Lead: Michelle Armstrong

Timeline: Summer 2017 - Spring 2019

- Activity 2.4: Continue to build relationships with state and regional librarians, repository staff, and other data managers.

Description: Connecting with people in the Northwest region with shared interests in research data will help the Research Data Management Group build professional networks. Setting up a listserv will allow the group to share resources and ask questions from professionals at other institutions. A semi-regular virtual meeting with librarians, repository staff, and other data managers in the region will facilitate relationship building.

Lead: Amber Sherman

Timeline: Summer 2017- Fall 2017

\section{Promote high quality data management practices through university-focused outreach and education activities.}

- Activity 3.1: Increase awareness of the importance and value of research data management through the implementation of a strategic communication plan.

Description: Researchers are often under great pressure to accomplish multiple goals. As a result, gaining the attention of faculty, staff, and students can be a significant roadblock to making progress in the delivery of data management services. Based on other successful outreach and marketing initiatives undertaken by the library, the Research Data Management Group will develop a communication plan focused on campus-wide and point-of-need communications. Lead: Megan Davis and Heather Grevatt

Timeline: Spring 2018 - Summer 2018 
- Activity 3.2: Create targeted support materials (checklists, helpful tips, FAQs, etc.) in response to campus researchers' needs.

Description: Researchers require point-of-need assistance that may not be facilitated by current support materials. Using responses from the Faculty Needs Assessment, Research Data Management Environmental Scan, and anecdotal evidence, the Research Data Management Group will develop support materials that better address researcher knowledge gaps while complimenting the ways in which they typically seek out information or support.

Lead: Albertsons Library Research Data Management Group

Timeline: Summer 2017 - Spring 2018

- Activity 3.3: Implement and assess the library's data management instruction modules.

Description: Online data management instruction modules were created in 2016 to assist faculty members teaching graduate research courses in introducing these skills to their students. To maximize use of these modules, the library will work with 4 courses to adopt the curriculum. During this phase, assessment of the content, format, and implementation of these modules will also take place. Based on assessment results, needed revisions will be made in order to improve the curriculum.

Lead: Megan Davis

Timeline: Summer 2017 - Spring 2019

- Activity 3.4: When communicating with researchers, provide information about data management best practices and available library supports to achieve those standards.

Description: Most researchers engage in some form of data management. However, few have received formal training in this area or are part of a discipline with established data management standards. Consequently, researchers do not always have the skills or knowledge to maximize the benefits of their data outputs. When consulting on creating, analyzing, archiving, and publishing research data, the Research Data Management Group will promote established or standards-based best practices. To ensure the effective implementation of these practices, the group will also inform researchers about relevant library supports and any related university policies.

Lead: Albertsons Library Research Data Management Group

Timeline: Summer 2017 - Spring 2019

\section{Assist researchers in creating high quality, actionable data management plans.}

- Activity 4.1: Create a standards based rubric to be used when reviewing data management plans.

Description: Reviewing a researcher's data management plan is a growing service provided by the library's Research Data Management Group. In order to build out this service, a rubric will be created based on internal and external standards and available institutional resources. This rubric will allow the group to help researchers create good data management plans regardless of 
grant requirements. A rubric will also allow group members to maximize inter-rater reliability when reviewing plans. The standards that are developed with the rubric will be communicated to researchers in an appropriate manner.

Lead: Megan Davis and Michelle Armstrong

Timeline: Spring 2018 - Summer 2018

- Activity 4.2: Formalize the data management plan review and evaluation process utilized by library staff.

Description: Over the last year and a half, the Research Data Management Group has been responding to requests for reviews of data management plans. Through this work, a basic approach to this service has developed. To ensure a high quality and timely delivery, the library will detail the processes and standards used for the reviews. The Research Data Management Group will also outline the levels of services we are able to provide. By doing this, group members will be able to efficiently and consistently assist researchers in submitting competitive grants, identify university resources committed to the project, and help integrate the data management planning process into a complete research lifecycle service model.

Lead: Michelle Armstrong and Heather Grevatt

Timeline: Summer 2017 - Fall 2017 (first draft)

- Activity 4.3: Evaluate and report upon the usefulness of the DMPTool for Boise State researchers.

Description: Created with funding from the National Science Foundation, the DMPTool provides a platform to help researchers create funder compliant data management plans for their grant applications. Although useful, anecdotal information has indicated that researchers struggle to understand the purpose, structure, and content needed for an effective and feasible plan. Additionally, suggested language provided through the tool appears to create more problems by encouraging researchers to commit university resources in ways that are not appropriate for their grant project. The Research Data Management Group will evaluate the DMPTool to determine if appropriate customizations can be made for Boise State researchers and if educational materials will help when utilizing the tool. If it is determined the DMPTool is not the best option, the group will provide information to campus partners and through the library's web site regarding alternatives.

Lead: Megan Davis and Michelle Armstrong

Timeline: Summer 2018 - Fall 2018 


\section{Establish methods for ensuring implementation of and accountability for research data management plans.}

- Activity 5.1: Iterate and formalize a data management plan implementation process.

Description: Once a grant is funded, researchers are responsible for implementing and reporting upon the approved data management plan. However, it can be challenging for researchers to do so with the numerous responsibilities and competing time commitments they face. Therefore, the Research Data Management Group will help researchers implement their specific data management plan while using best practices throughout their research project. Additionally, the group will design supports to reduce the time and resource burden on the researcher.

Lead: Albertsons Library Research Data Management Group

Timeline: Summer 2017 - Spring 2019

- Activity 5.2: Review, annotate, and make accessible tools and software used for producing and managing research data.

Description: There are a number of software programs and online tools available to help researchers produce, manage, analyze and visualize their research data. Some of these tools require a subscription, training, or are discipline-specific. The Research Data Management Group will search for and review data management tools, create an annotated list on the data management website, and work with campus partners in OIT and Research Computing to make them accessible to researchers.

Lead: Amber Sherman

Timeline: Summer 2018 - Fall 2018

6. Provide the technological and procedural infrastructure (tools, policies, direct services, staffing, etc.) to actively curate and make discoverable Boise State's research data.

- Activity 6.1: Document the ScholarWorks research data ingest workflow.

Description: Data curation and ingest of data sets to ScholarWorks involves many steps and one librarian is currently primarily responsible. Documenting the process will allow all members of the Research Data Management Group to use the documentation in case of absence. A manual detailing decisions will ensure consistency across time and people involved in the project. As new standards for data curation are introduced, the documentation can be updated to allow for a more efficient workflow. Each step of the data ingest process will be recorded and explained and shared on a Google Site available to members of the Research Data Management Group. The parts of the documentation that are relevant to other campus stakeholders will be shared appropriately.

Lead: Amber Sherman

Timeline: Summer 2017 - Fall 2018 
- Activity 6.2: Utilizing information gathered in the previous 2-year strategic agenda period, work with faculty to publicly share their existing research data.

Description: During Phase I, the Research Data Management Group found over 500 original data sets referenced in recent articles published by Boise State authors, but less than one percent were publicly accessible. Contacting these authors and helping them curate their data sets for public sharing will provide greater discoverability and use of Boise State's data assets. The Research Data Management Group will also continue to work with other researchers as they publish and find out about the data curation services.

Lead: Amber Sherman

Timeline: Summer 2017 - Spring 2019

- Activity 6.3: Explore becoming a DataONE Member Node.

Description: One of the most important ways of increasing the visibility of the work of Boise State researchers is to make data sets available through publicly accessible data repositories. DataONE is "the foundation of new innovative environmental science through a distributed framework and sustainable cyberinfrastructure that meets the needs of science and society for open, persistent, robust, and secure access to well-described and easily discovered Earth observational data" (https://www.dataone.org/what-dataone). Given the number of Geosciences data sets ingested to ScholarWorks during Phase I, becoming a Member Node of DataONE will facilitate greater discoverability of Boise State Geosciences data with the environmental science community.

Lead: Amber Sherman and Michelle Armstrong

Timeline: Spring 2019

\section{Assess the effectiveness and impact of the library's data management services.}

- Activity 7.1: At the end of the two year strategic agenda period, provide university administrators a comprehensive report that include both statistical and descriptive information about the university's research data assets.

Description: As data management activities continue to increase across campus, decisions about planning and allocation of resources should be informed by quantitative data. Working with other university groups, the library will gather information about the number of data sets created at Boise State, how these assets have been publicly shared, usage of these data sets, and university resources required to manage the data sets. This information will help articulate the need for adequate staffing and other researcher supports in this area.

Lead: Albertsons Library Research Data Management Group

Timeline: Spring 2019 


\section{Research Data Management Group Members}

Michelle Armstrong

Associate Professor/ Scholarly Communications and Data Management Librarian

michellearmstrong1@boisestate.edu

(208) 426-2580

Heather Grevatt

Assistant Professor/ Research and Instruction

Librarian

heathergrevatt@boisestate.edu

(208) 426-3737
Megan Davis

Assistant Professor/ Research and Instruction

Librarian

megandavis3@boisestate.edu

(208) 426-1621

Amber Sherman

Assistant Professor/ Scholarly Communications and Data Management Librarian

ambersherman704@boisestate.edu

(208) 426-4302 
Appendix A: 2017-2019 Data Management Strategic Agenda

1.1 Build liaison skills

1.2 Metadata librarian

1.3 Increase RDM Group's skills

1.4 Increase RDM Group

coverage

1.5 Create cost estimate process

2.1 Identify core

processes/services

2.2 Data-related policies

2.3 University stakeholder

agreements

2.4 Build external relationships

3.1 Strategic communication plan

3.2 Create support materials

3.3 Implement/assess curriculum

3.4 Provide best practice information 
Appendix A: 2017-2019 Data Management Strategic Agenda

4.1 Create DMP review rubric

4.2 Formalize DMP review service

4.3 Evaluate DMP Tool

5.1 Formalize DMP

implementation process

5.2 Review tools \& software

6.1 Document SW ingest workflow

6.2 Work with faculty on sharing data

6.3 Explore DataONE membership

7.1 Write comprehensive report detailing research data assets 